\title{
Determinants of Technical Efficiency of Paddy Cultivators: A Study of Hailakandi District in Assam
}

\author{
Manik Gupta, ${ }^{1}$ Ashish Taru Roy, ${ }^{2}$ Uttam deb $^{3}$ and Ritwik Mazumder ${ }^{4}$ \\ (Department of Economics, S.K.Roy College, India) \\ (Department of Economics, Assam University, India) \\ (Department of Economics, Assam University, India) \\ (Department of Economics, Assam University, India)
}

\begin{abstract}
The study measures farm level technical efficiency among paddy of Hailakandi district of Assam on the basis of farm level primary data of 265 cultivators for the cropping season of 2010-11. A translog stochastic production frontier is estimated and selected non-input factors are assumed to explain farm level variations in technical inefficiency. Among the non-input factors age and education levels of the cultivator have positive influences on technical efficiency. However indebtedness and percentage of self consumption of farm turn out have negative influences. Government support through agricultural department has an insignificant impact on technical efficiency. Proportion of land leased in by the cultivator has a positive impact on technical efficiency. Decreasing returns to scale is apparent from the parameter estimates. Mean technical efficiency is found to be around 63 percent. The study observes negative association between farmers' distress and the level of technical efficiency.
\end{abstract}

Keywords: Decreasing return to scale, Hailakandi, Non-input factors, Technical efficiency, Translog stochastic production frontier

\section{Introduction}

Assam has a predominantly humid sub-tropical climate with hot and humid summers, severe monsoons and mild winters. A significant feature of the cropping patterns of the region is the pre-dominance of paddy, which accounts for more than 90 percent of total cropped area. Distinctions are drawn between three different paddy crops, namely, Ahu paddy, Shali paddy and Boro paddy depending on the harvesting season. The present study attempts to measure farm level technical efficiency among Ahu paddy farmers in Hailakandi district of Assam by adopting a transcendental logarithmic stochastic production frontier approach with inefficiency effects. A host of non-input and socioeconomic factors which might affect farm level technical efficiency are taken into consideration to explain inter-farm variations in the level of technical efficiency. Efficiency differentials across different size classes of cultivators are also studied.

During the past three decades numerous studies have been conducted on measurement of efficiency in agriculture and as such vast literature has accumulated since the early 1980s. For instance Wadud and White (2002) [1] measured farm specific technical inefficiency using farm level cross sectional survey data of rice farmers in Bangladesh. The results show that technical inefficiency effects tend to be significantly influenced by the factors measuring environmental degradation and irrigation infrastructure. More influential contributions are due to Kalirajan and Shand (1989) [2], Kalirajan and Flinn (1983) [3], Ali and Flinn (1989) [4], Coelli and Battese (1996) [5], Heshmati and Kumbhakar (1997) [6] and Kumbhakar and Bhattacharyya (1992) [7), Bagi and Huang (1983) [8] and Bhattacharyya, Kumbhakar and Bhattacharyya (1995) [9].

This paper is written in the following four sections. A brief introduction to the study is given in section I, followed by methodology and data sources in section II. Section III deals with the presentation of empirical results and analysis and finally summary of the study and policy conclusions are presented in section IV. Throughout the text the terms 'farmer' and 'cultivator' have been used alternatively assuming that they have the same meaning.

\subsection{Econometric Approach}

\section{Methodology and Data}

The present study uses the technical inefficiency effects model originally due to Kumbhakar, Ghosh and McGuckin (1991) [10], and estimates the stochastic frontier and the inefficiency effects model parameters simultaneously, given appropriate distributional assumptions on the inefficiency random variable (Battese and Coelli, 1995) [11]. The simultaneous estimation of the stochastic production frontiers and models of technical inefficiency using maximum likelihood techniques have also been further developed by Reifschneider and 
Stevenson (1991) [12], Huang and Liu (1994) [13], and Battese and Coelli (1995) [14]. This approach has been applied empirically by Coelli and Battese (1996) [15] and Battese and Broca (1997) [16].

A number of studies have used a two step approach to determine the sources of inefficiency or factors that affect farm level technical inefficiency. In the first step a stochastic frontier model is estimated by maximum likelihood method and farm specific technical inefficiencies are calculated under the assumption that the technical inefficiency effects are identically distributed. In this step it is ignored that technical inefficiency is a function of farm specific and exogenous variables. Once farm level technical inefficiencies are estimated it is regressed in the second stage on a set of farm specific factors (or characters) and/or exogenous factors beyond the farm's direct control but which may explain inter-farm variation in technical inefficiency. These factors typically are not inputs but may affect the way inputs are organised in production. In this step either logit or probit models are used. The application of the logit or probit in the second step contradict the assumption of identically distributed inefficiency effects in the stochastic frontier model since predicted efficiencies are assumed to have a functional relationship with farm specific variables and exogenous variables. In the second stage the estimated technical inefficiency effects are modeled as a function of some farm specific and exogenous factors. This implies that inefficiency effects are not identically distributed unless the coefficients of the farm specific factors are simultaneously equal to zero (Kumbhakar and Lovell, 2000) [17].

The problems of this two stage method can be addressed using a one stage formulation of Kumbhakar, Ghosh and McGuckin (1991) [18]. They specified the technical inefficiency effects and estimated the stochastic frontier and inefficiency effects simultaneously by using maximum likelihood method, given appropriate distributional assumptions on the inefficiency component. Kumbhakar et al (1991) [19] model was developed for cross-sectional data. Reifschneider and Stevenson (1991) [20] and later, Huang and Liu (1994) [21] also developed the one stage formulation based on cross-sectional data. Battese and Coelli (1995) [22] developed a model similar to Kumbhakar et al (1991) [23] but for panel data. The present study follows a Kumbhakar et al (1991) [24] approach to simultaneously measure farm level technical efficiency and to test the impact of a few (selected) farm specific and non-input factors on the level of technical inefficiency among paddy cultivators of Hailakandi district of Assam on the basis of primary data (covering 200 cultivators) collect Jun - July, 2010. Exact description of all relevant variables used in the study is imperative. The list of variables with their units of measurement for the translog production frontier model is listed below.

Output (Y) of the cropping season of 2010 in quintals, cultivated area (CA) in bigha, cost of human labour (HL) including women workers in rupees, cost of traditional equipments ( $\mathrm{E}$ in rupees), expenditure in rupees on irrigation (I) facilities (including personalized micro-irrigation system - i.e. pump sets etc.), value of fertilizers (F) in rupees, and value of pesticides $(\mathrm{P})$ in rupees. Bigha (and not hectare) has been kept as the unit of cultivated area as because there is a predominance of small and medium sized plots across the sample under consideration.

The list of variables with their units of measurement for the inefficiency effects model are, age of the cultivator as a proxy for experience, education as measured by total no. of years of schooling in the cultivator's household, existing loans in rupees, area under HYV, self consumption as a percentage of output, government support dummy (recipient of any technical help and support from the State Dept. of Agriculture $=1,0$ otherwise), multiple b dummy (multiple croppers $=1,0$ otherwise). The econometric model is presented in the Appendix (see appendix 2).

\subsection{Data}

Data for the present study is completely primary in nature based on paddy production for the Ahu cropping season of 2010. The timing of sowing for Ahu paddy is around March-April and the timing of harvest is around June-July. Ahu is the second largest crop both in terms of area sown and total output. Moreover it is entirely rainfall dependent or monsoon dependent as because privately arranged artificial irrigation facilities (like electric or diesel driven pump sets to draw ground water) are rare in South Assam and especially so in Hailakandi.

The sampling strategy is illustrated in the Table 1 given in the appendix. All the five blocks of Hailakandi district were selected for the study. In stage 1, approximately 30 percent of the Gram Panchayats under each block were randomly selected. In other words 4 Gram Panchayats (G.P.) was randomly chosen from a block consisting of 12 G.P.s. In stage 2 the best village in terms of agricultural performance of the last cropping season (as per secondary information) was chosen from each of the selected G.Ps. Thus only one village (best performing village in terms of paddy output) was selected from a G.P. Evidently number of G.P.s selected equals the number of villages selected for the study.

A slightly more complicated strategy was adopted for the purpose of cultivator selection. A'priori information on size-class shows that sub-marginal, marginal and small farmers dominate the region. From each selected village the complete list of farmers according to size class was first obtained from the Agricultural Circle Officer. Finally, 1 percent of sub-marginal farmers, 1 percent of marginal farmers, 2 percent of small 
farmers, 10 percent of medium size class farmers and 50 percent of large farmers were chosen randomly from each selected village. The village wise samples obtained are given in the sampling chart in table 1 in the appendix. The total sample size for the present study is 265 .

\section{Analysis of Empirical Results}

The size-class wise distribution of operational holdings of the sample of 265 cultivators considered in the present study is presented in Table 2 of Appendix 1. Approximately 17 percent of the total sample of cultivators belong to the sub-marginal size class ( 0 - 5 bigha). On the other hand 27 percent of sample cultivators belong to the marginal size class, which is basically below 1 hectare size class. Around 17 percent of sample cultivators belong to the 'small' size class (that is 1- 2 hectare size class). Thus sub-marginal, marginal and small farmers comprise 51 percent of sample cultivators. Interestingly these 51 percent sample cultivators enjoy around 22 percent of total operational holding in the sample. Around 16 percent of sample cultivators belong to the semi-medium size class of farmers. However, their operational holding is around 33 percent of total operational holding in the sample. The medium size class of cultivators (4-10 hectare size-class) constitutes approximately 19 percent of the sample of cultivators. However, this size class enjoys around 40 percent of total operational holding in the sample. Finally only around 3.4 percent of total sample cultivators belonging to the large size class (above 10 hectare) they enjoy around 4 percent of total operational holding in the sample.

In sum, the distribution in the Table 2 reveals that the semi-medium and medium size class of cultivators dominates the sample in terms of land holding. However, semi-medium and medium sized cultivators comprise only 35 percent of sample cultivators but these two size classes together hold roughly 73 percent of operational holdings in the sample. Standard measures of inequality are not computed. Table 3 presents the data summary or descriptive statistics of all variables used to estimate the parameters of the translog stochastic production frontier. This is followed by Table 4, which presents the summary statistics of the inefficiency effects variables. Table 5 presents the maximum likelihood estimates of parameters of the translog production function. Evidently the parameters of the translog production function do not have any direct interpretation and as such the partial elasticities of output with respect to inputs are more pertinent. Even then estimated values of certain coefficients and $t$-ratios are worth noting.

The constant term is found to be insignificant. So are the coefficients of irrigation, fertilizers and pesticides. Cultivated area is statistically the most significant factor that determines output. This is followed by human labour and traditional firm equipments. Moreover, it is revealed from table 5, that all the interaction terms are not only statistically insignificant but have extremely small values and hence play a very negligible role in determining the elasticities of output with respect to factors.

Turning to the variance parameters of the stochastic frontier model it is found that both $\sigma^{2}=\sigma_{v}^{2}+\sigma_{u}^{2}$ and $\lambda=\sigma_{u} / \sigma_{v}$ are statistically significant (following the Aigner et al (1977) parameterization) [25]. This is an indication of the presence of inefficiency. This implies that OLS would be an inappropriate method to estimate parameters of the translog production function. Testing the null hypothesis no technical inefficiency is important. The null hypothesis of no technical inefficiency can be tested by applying the Likelihood Ratio Test. The likelihood ratio test is based on the likelihood ratio statistic (LR) defined as,

$$
L R=-2 \ln \left[L\left(H_{0}\right) / L\left(H_{A}\right)\right]
$$

where $L\left(H_{0}\right)$ and $L\left(H_{A}\right)$ are the values of the likelihood function (optimum) under the null and alternative hypotheses respectively. But since the hypothesized value of $\lambda$ lies on the boundary of the parameter space it is difficult to interpret the test statistic. It can be shown that the $L R$ statistic follows a mixed $\chi^{2}$ distribution that asymptotically approaches $\chi^{2}$ distribution with degrees of freedom equal to the number of restrictions imposed in the model (Coelli, 1995) [26]. Similar is the test of the hypothesis that inefficiency effects are absent in the model. All estimations were done using the software package FRONTIER 4.1 (Coelli, 1995) [27]. The Battese and Coelli (1995) [28] inefficiency effects model was adopted. The third central moment of OLS residuals is found to be -903.011 which is a fundamental requirement.

Obtaining the maximum likelihood estimates of all parameters of the traditional (OLS) model and inserting it back in the log likelihood function gives the optimum value of the log likelihood function under the null hypothesis of no technical inefficiency. For the null hypothesis no technical inefficiency the $L R$ statistic is computed at 50.48 which greater than $\chi^{2}$ with 8 degrees of freedom at 1 per cent level. Thus the hypothesis of no technical inefficiency is rejected at 1 per cent level. In other words traditional average production function (OLS) model would be an improper specification of the production function.

Estimated coefficients of the inefficiency effects variables of the translog production frontier are presented in Table 6 . The constant term $\gamma_{1}$ is found to be insignificant along with the coefficients of education and government support dummy. The coefficient of 'Age' of the cultivator is negative and statistically significant at 4 percent level. This implies that higher the age of the farmer, the lesser the technical inefficiency, 
or alternatively, higher the technical efficiency. Similarly percentage of land leased in by the cultivator negatively influences technical inefficiency, that is, positively influences technical efficiency. So higher is the percentage of land leased in by the cultivator, higher the technical efficiency. However, the coefficient of land leased is significant at 6 percent level and not at 5 percent level. Education as measured by number of years of formal schooling of the cultivator has positive influences on firm level technical efficiency but the coefficient of education is insignificant even at 10 percent level.

Outstanding loans which is taken as an indicator of indebtedness in the present study, has a strong and positive influence on technical inefficiency and the coefficient is found to be significant at 1 percent level. In other words, the more indebted the farmer the lower is the technical inefficiency. As mentioned before government support dummy is found to be insignificant. It may be inferred that government support or agricultural extension programmes did not have any significant influence on farm level technical efficiency for the selected sample of cultivators. Self consumption as a percentage of firm output negatively influences technical efficiency, the coefficient being significant at 9.3 percent. In other words farmers' distress in a relative sense negatively influences technical efficiency. For the present study percentage of self consumption is taken as a proxy for farmers' distress.

Given the backwardness of agriculture in the region, it appears that farmers with larger proportion of self consumption (as a percentage of farm produce) are relatively more distressed compared to those having a smaller percentage of self consumption. The simple correlation coefficient between area cultivated and percent of self consumption turns out to be -0.67 implying that larger the farm size smaller the percentage of self consumption, the converse being also true. More interestingly the simple correlation coefficient between output size and percentage of self consumption turns out to be -0.54 , which is consistent with the farm size - self consumption relation. Thus the findings indicate that more distressed farmers are technically more inefficient. Finally the correlation coefficient between self-consumption and indebtedness is 0.33 which is positive. That is higher the indebtedness higher is the distress level. This establishes the vicious chain of distress level, self consumption and indebtedness.

Finally, the partial elasticities of output with respect to inputs computed on the basis of the estimated parameters of the translog production function are presented in Table 7. Cultivated area has the highest elasticity value (0.62) among all other inputs. This is followed by human labour. The remaining inputs consider in the study such as equipments, irrigation, fertilizers and pesticides have negligible elasticity values. The returns to scale or the scale elasticity of output (which is basically the sum of the partial input elasticities) turns out to 0.869 which is less than unity.

Thus for given sample of farmers in Hailakandi district no evidence of increasing return to scale is found. This is primarily on account of the poor values of output elasticities with respect to equipments, irrigation, fertilizers and pesticides. Arguably this is a steady finding in the framework of the present study where personal or privately organised irrigation is expensive (if not beyond the financial capability of most cultivators) and its use is infrequent. Furthermore controlled use of fertilizers and pesticides are rare in the sense that their application per bigha, are on most occasions, far below standard agricultural prescriptions yielding suboptimal results.

\section{Summary and Conclusions}

The present study measures farm level technical efficiency of paddy farmers in Hailakandi district of Assam by adopting a stochastic production frontier with inefficiency effects for cross-sectional data. The stochastic frontier and the inefficiency effects parameters are simultaneously estimated using maximum likelihood method (Battese and Coelli, 1995) [25]. A transcendental logarithmic production frontier is adopted due to its flexibility. With due reservations, the study is based on paddy output of the agricultural season of 2010-11 (i.e., Ahu) only. Area sown, labour, irrigation, pesticides and fertilizers are the key inputs assumed to explain farm output. As per district level agricultural records, farm mechanization and automation are too rare to be considered as inputs for the sample of cultivators chosen in the present study. Certain non-input factors which usually affect farm level technical efficiency are assumed to explain inter-farm variations in the level of technical efficiency.

All five blocks of Hailakandi district were selected for the study. Approximately 30 percent of the Gram Panchayats (G.P.s) under each block were randomly selected. The best village in terms of agricultural performance of the last cropping season (as per secondary information) was chosen from each of the selected G.P.s. Only one village (best performing village in terms of paddy output) was selected from a G.P. All size classes of cultivators were appropriately included from a selected village in order to construct a representative sample of 265 cultivators covering all blocks of the district.

The principal findings of the study turn out to be rather interesting but are more or less obvious in the context of backward agriculture where mono-cropping is predominant. A noteworthy finding is that semimedium and medium size classes of cultivators dominate the sample in terms of land holding. To be precise, 
semi-medium and medium sized cultivators comprise only 35 percent of sample cultivators but together enjoy around 73 percent of operational holdings in the sample.

Turning to the estimates of trans-log production function parameters, the constant term is found to be insignificant. So are the coefficients of irrigation, fertilizers and pesticides. Cultivated area is statistically the most significant factor that determines output. This is followed by human labour and traditional firm equipments. Moreover, all the interaction terms are not only statistically insignificant but have extremely small values and hence play a very negligible role in determining the elasticities of output with respect to factors. The elasticities of output with respect to inputs are more important and are computed from the estimated parameters of the translog production function.

Cultivated area has the highest elasticity value (0.62) among all other inputs. This is followed by human labour. The remaining inputs consider in the study such as equipments, irrigation, fertilizers and pesticides have negligible elasticities. The scale elasticity of output is less than unity which clearly indicates decreasing returns to variable inputs.

Poor scale elasticity is primarily due to the poor output elasticities with respect to almost all inputs. Arguably this is consistent in the context of backward agriculture where personal or privately organised irrigation is not beyond the financial capability of most cultivators and thus its use is irregular and below prescribed norms. Moreover controlled use of fertilizers and pesticides are rare and their application per bigha, are on most occasions, far below standard agricultural prescriptions leading to suboptimal outcomes. These factors might explain the poor sensitivity of output with respect to inputs.

The null hypothesis of no technical inefficiency in the data was statistically tested using Likelihood Ratio Test. The results strongly signify that technical inefficiency is present in the data set. This further implies that traditional least squares method would be inappropriate to estimate parameters of the production function. This is also apparent from the statistically significant values of the variance parameters of the stochastic frontier model.

The influences of non-input factors on farm level technical inefficiency are rather more crucial. Among the non-input factors years of formal education of the cultivator positively influences technical efficiency but the coefficient is found to be statistically insignificant. The coefficient of government support dummy is also found to be statistically insignificant. However both indebtedness (as measured by outstanding loans) and percentage of self consumption of farm produce have negative influences on technical efficiency. Interestingly, percentage of land leased-in by the cultivator has a positive impact on technical efficiency and the coefficient is found to be significant. Surprisingly age of the cultivator has a positive impact on technical efficiency. That is the older and more experienced farmers are technically more efficient. Mean technical efficiency for the sample of 265 cultivators is approximately 63 percent.

The study concludes that, given the backwardness of agriculture in the region, farmers with larger proportion of self consumption (as a percentage of farm produce) are relatively more distressed compared to those having a smaller percentage of self consumption. The simple correlation coefficient between area cultivated and percent of self consumption is found to be negative implying that larger farmers have smaller percentage of self consumption. Moreover the correlation coefficient between output size and percentage of self consumption is also negative implying that more successful farmers have smaller percentage of selfconsumption. Expectedly, proportion of self-consumption is positively associated with indebtedness for the present sample of cultivators. Thus the findings indicate that more distressed farmers are technically more inefficient.

\section{References}

[1] Wadud, A. Md. and White, B., The determinants of technical inefficiency of farms in Bangladesh, Indian Economic Review, 2 2002, 183-97.

[2] Kalirajan, K. and Shand, R. T., A generalized measure of technical efficiency, Applied Economics, 21, 1989, $25-34$.

[3] Kalirajan, K. and Flinn, J. C., The measurement of farm specific efficiency, Pakistan Journal of Applied Economics, 2, 1983, 16780 .

[4] Ali, M. and Flinn, J. C., Profit efficiency among Basmati rice producers in Pakistan Punjab, American Journal of Agriculture Economics, 71, 1989, 303-30.

[5] Coelli, T. and Battese, G. E., Identification of factors which influence the technical inefficiency of Indian farmers, Australian Journal of Agricultural Economics, 40, 1996, 103-128.

[6] Heshmati, A and Kumbhakar, S. C., Estimation of technical efficiency in Swedish crop farms, A pseudo panel data approach, Journal of Agriculture Economics, 48, 1997, 22-37.

[7] Kumbhakar, S. C. and Bhattacharya, A., Price distortion and resource use efficiency in Indian agricultural: A restricted profit function approach', Review of Economics and Statistics, 74, 1992, 221-39.

[8] Bagi, F. S. and Huang, C. J. Estimating production technical efficiency for individual farms tennessee, Canadian Journal of Agricultural Economics, 3(2), 1983, 249-256.

[9] Bhattacharyya, A., Kumbakar, S. C. and Bhattacharyya, A., Ownership structure and cost efficiency: A study of publicly owned passenger bus transportation companies in India, Journal of Productivity Analysis, 6(1), (April), 1995, 47-62.

[10], [18], [19], [23] \& [24] Kumbhakar, S. C., Ghosh, S. and McGuckin, T. J., A generalized production frontier approach for estimating determinants of inefficiency in U.S. dairy farms, Journal of Business and Economic Statistics, 9( 3), 1991, $287-96$. 
[11], [14], [22] \& [28] Battese, G. E. and Coelli, T., A model for technical inefficiency effects in a stochastic frontier production function for panel data, Empirical Economics, 20(2), 1995, 325-32.

[12] \& [20] Reifschneider, D. and Stevenson, R., Systematic departures from the frontier: A framework for analysis of farm inefficiency,' International Economic Review, 18, 1991, 435-44.

[13] \& [21] Huang, C. J., and Liu, J. T., Estimation of a Non-Neutral Stochastic Frontier Production Function, Journal of Productivity Analysis, 5(2), 1994, 171-80.

[16] Battese, G. E. and Broca, S. S., Functional forms of stochastic frontier production functions and models for technical inefficiency effects: A comparative study for Wheat farmers in Pakistan, Journal of Productivity Analysis, 8, 1997, 395-414.

[17] Kumbhakar, S. C. and Knox Lovell, C. A., Stochastic frontier analysis, (Cambridge University Press, NY, 2000).

[25] Aigner, D., Lovell, C. A. K. and Schmidt, P., Formulation and estimation of stochastic production models, Journal of Econometrics, $6,1977,21-37$.

[26] \& [27] Coelli, T., 'Estimators and Hypothesis Tests for a Stochastic Frontier Function: A Monte Carlo Analysis,' Journal of Productivity Analysis, 6(4), 1995, 247-68.

\section{Appendix 1}

Tables

Table 1. Block and Village wise sampling chart

\begin{tabular}{cllc}
\hline Block & \multicolumn{1}{c}{ G.P. selected } & \multicolumn{1}{c}{ Village selected } & $\begin{array}{c}\text { Sample } \\
\text { Size }\end{array}$ \\
\hline Algapur & (a) Kanchanpur & Dolidar grant & 16 \\
& (b) Chandipur & Chandipur -2 & 19 \\
& (c) Mohanpur & Mohanpur-1 & 25 \\
& (d) Nitai Nagar & Nitai Nagar & 13 \\
Hailakandi & (a) Bahadurpur & Bahadurpur -i & 11 \\
& (b) Narainpur & Narainpur -i & 9 \\
& (c) Sudarsanpur & Sudarsanpur -i & 13 \\
South Hailakandi (a) jamira G.P. & Jamira -i & 6 \\
& (b) Karicherra Darirghat & Dariarghat - & 19 \\
& (c) Paloicherra & Paloicherra -i & 7 \\
& (d) Baruncherra -Kukicherra Kukicherra grant & 17 \\
Katlicherra & (a) Dinonathpur & Dinonathpur -i & 14 \\
& (b) Rangabak & Rangabak -ii & 12 \\
& (c) Sahabad & Sahabad-i & 11 \\
Lala Block & (a) Sudarsanpur Kalacherra Sudarsanpur -i & 20 \\
& (b) Purbakittarbond- & Rajyeswerpur -i & 11 \\
& (c) Nimaichandpur & Nimaichandpur -i & 14 \\
& (d) Chandrapur & Chandrapur-i & 12 \\
& (e) Dholcherra -Bilaipur & Lalpani F.V. & 16 \\
\hline
\end{tabular}

Table 2. Frequency Distribution of Operational Holdings in the Sample

\begin{tabular}{|c|c|c|c|}
\hline Size Class & No. of Cultivators & $\begin{array}{l}\text { Percentage } \\
\text { of total } \\
\text { sample of } \\
\text { cultivators }\end{array}$ & $\begin{array}{l}\text { Percentage } \\
\text { of total operational holding } \\
\text { in the sample }\end{array}$ \\
\hline $\begin{array}{l}\text { Sub-marginal } \\
(0-5 \text { bigha })\end{array}$ & 45 & 16.98 & 5.09 \\
\hline $\begin{array}{l}\text { Marginal } \\
(<1 \text { hectare })\end{array}$ & 72 & 27.16 & 5.11 \\
\hline $\begin{array}{c}\text { Small } \\
(1-2 \text { hectare })\end{array}$ & 45 & 16.98 & 12.33 \\
\hline $\begin{array}{l}\text { Semi medium (2- } 4 \\
\text { hectare) }\end{array}$ & 43 & 16.22 & 33.41 \\
\hline $\begin{array}{c}\text { Medium (4 - } 10 \\
\text { hectare) }\end{array}$ & 51 & 19.24 & 39.95 \\
\hline Large ( $>10$ hectare) & 9 & 3.42 & 4.11 \\
\hline Total & 265 & 100 & 100 \\
\hline
\end{tabular}


Source: Author's estimates based on sample observations.

Table 3. Summary Statistics of Variables of the Translog Production Function*

\begin{tabular}{cccccc}
\hline Variables & Sample mean & Min & Max & S.D. & C.V. \\
\hline Y & 163.48 & 10 & 800 & 147.21 & 0.900 \\
CA & 17.71 & 2 & 65 & 11.18 & 0.63 \\
HL & 73.91 & 30 & 241 & 35.098 & 0.47 \\
E & 5645.36 & 900 & 127598 & 11757.62 & 2.082 \\
I & 1744.68 & 0 & 4500 & 1431.08 & 0.820 \\
F & 2364.68 & 0 & 24920 & 3351.19 & 1.4171 \\
P & 1002.16 & 0 & 18550 & 1965.65 & 1.9614
\end{tabular}

Source: Author's estimates based on sample observations.

*Units of measurement of each variable are mentioned in Section 2.1

\begin{tabular}{lccccc}
\hline \multicolumn{5}{c}{ Table 4. Summary Statistics of Inefficiency Effects Variables } \\
\hline \multicolumn{1}{c}{ Variables } & $\begin{array}{c}\text { Sample } \\
\text { mean }\end{array}$ & Minimum & Maximum & S.D & C.V \\
\hline $\begin{array}{l}\text { Outstanding } \\
\text { Loans }\end{array}$ & 2835.96 & 2100 & 95000 & 13002.96 & 4.584 \\
Land leased & 1.99 & 3 & 24 & 9.64 & 4.84 \\
Self & 50.65 & 0 & 25 & 40.31 & 0.7958 \\
consumption & 4.21 & 1 & 11 & 2.87 & 0.68 \\
$\begin{array}{l}\text { Education } \\
\text { Age }\end{array}$ & 43.7 & 37 & 69 & 11.11 & 0.25 \\
\hline
\end{tabular}

Source: Author's estimates based on sample observations.

Table 5. Maximum Likelihood Estimates of Parameters of Trans-log Production Frontier

\begin{tabular}{|c|c|c|}
\hline Coefficients of & Estimated Value & $t$-Value \\
\hline Constant & 1.097 & 1.009 \\
\hline $\mathrm{CA}$ & 0.060 & 2.890 \\
\hline HL & 0.001 & 2.46 \\
\hline $\mathrm{E}$ & 0.378 & 1.98 \\
\hline I & 0.366 & 0.079 \\
\hline $\mathrm{F}$ & 0.217 & 0.189 \\
\hline $\mathrm{P}$ & 0.0001 & 0.911 \\
\hline $\mathrm{CA} \times \mathrm{CA}$ & -0.0003 & -0.931 \\
\hline $\mathrm{HL} \times \mathrm{HL}$ & -0.005 & -0.456 \\
\hline $\mathrm{E} \times \mathrm{E}$ & 0.016 & 0.011 \\
\hline $\mathrm{I} \times \mathrm{I}$ & 0.0007 & -1.342 \\
\hline $\mathrm{F} \times \mathrm{F}$ & 0.1178 & 0.547 \\
\hline $\mathrm{P} \times \mathrm{P}$ & 0.0877 & 0.722 \\
\hline $\mathrm{CA} \times \mathrm{HL}$ & 0.0002 & 0.215 \\
\hline $\mathrm{CA} \times \mathrm{E}$ & 0.00001 & 0.004 \\
\hline $\mathrm{CA} \times \mathrm{I}$ & $0.01 \times 10^{-5}$ & $0.09 \times 10^{-4}$ \\
\hline $\mathrm{CA} \times \mathrm{F}$ & $0.03 \times 10^{-5}$ & $0.02 \times 10^{-3}$ \\
\hline $\mathrm{CA} \times \mathrm{P}$ & $0.07 \times 10^{-6}$ & 0.051 \\
\hline $\mathrm{F} \times \mathrm{P}$ & $-0.11 \times 10^{-5}$ & -0.008 \\
\hline $\mathrm{HL} \times \mathrm{E}$ & $-0.012 \times 10^{-5}$ & -0.045 \\
\hline $\mathrm{HL} \times \mathrm{I}$ & $0.087 \times 10^{-4}$ & 0.115 \\
\hline $\mathrm{HL} \times \mathrm{F}$ & $-0.058 \times 10^{-3}$ & -0.015 \\
\hline $\mathrm{HL} \times \mathrm{P}$ & $0.077 \times 10^{-4}$ & $0.04 \times 10^{-3}$ \\
\hline $\mathrm{E} \times \mathrm{I}$ & $0.001 \times 10^{-5}$ & 0.001 \\
\hline $\mathrm{E} \times \mathrm{F}$ & $0.025 \times 10^{-6}$ & 0.113 \\
\hline $\mathrm{E} \times \mathrm{P}$ & $0.017 \times 10^{-4}$ & $0.17 \times 10^{-3}$ \\
\hline
\end{tabular}




\begin{tabular}{lll}
$\mathrm{I} \times \mathrm{F}$ & $-0.015 \times 10^{-7}$ & -0.089 \\
$\mathrm{I} \times \mathrm{P}$ & $-0.013 \times 10^{-8}$ & $-0.903 \times 10^{-4}$ \\
\hline Variance parameters & & \\
\hline$\sigma^{2}=\sigma_{v}^{2}+\sigma_{u}^{2}$ & 0.035 & $8.005^{*}$ \\
$\lambda=\sigma_{u} / \sigma_{v}$ (Aigner et al 1977$)$ & 0.359 & $2.500^{*}$ \\
$\sigma_{v}^{2}$ & 0.031 & \\
$\sigma_{u}^{2}$ & 0.004 & \\
$\begin{array}{l}\text { Log Likelihood Value } \\
3^{\text {rd }} \text { Central Moment of OLS }\end{array}$ & -1.110 & \\
Residuals & -903.011 & \\
\hline ce : Authors' estimates based on primary data using econometric package FRONTIER 4. I for Windows.
\end{tabular}

Source: Authors' estimates based on primary data using econometric package FRONTIER 4.1 for Windows.

\begin{tabular}{lcc}
\hline Table 6. Estimated Coefficients of the Inefficiency Effects Variables of the Trans-log Production Frontier \\
\hline Coefficients of & Estimated Value & $t$-Ratios \\
\hline Constant & 0.006 & 0.991 \\
Age & -0.256 & -1.819 \\
Outstanding Loans & 8.956 & 3.688 \\
Land Leased & -0.222 & -1.556 \\
Education & -0.007 & -1.008 \\
Self Consumption & 3.476 & 1.333 \\
Govt. Support & 0.90 & 0.001 \\
\hline
\end{tabular}

Source: Authors' estimates based on primary data using econometric package FRONTIER 4.1 for Windows.

\begin{tabular}{ccc}
\hline Table 7. Estimated Output Elasticities of Inputs based on Estimated Trans-log Production Function Parameters \\
\hline Inputs & Elasticity \\
\hline CA & 0.62 \\
HL & 0.11 \\
E & 0.07 \\
I & 0.005 \\
F & 0.06 \\
P & 0.004 \\
Returns to Scale & 0.869 \\
\hline
\end{tabular}

Source: Authors' calculations based on econometric estimates based on primary data.

\begin{tabular}{ccc}
\hline \multicolumn{3}{c}{ Table 8. Frequency Distribution of } \\
Firm Level Technical Efficiency \\
\hline $\begin{array}{c}\text { Percentage Technical } \\
\text { Efficiency (TE) }\end{array}$ & Frequency & $\begin{array}{c}\text { Percentage of } \\
\text { Sample Farms }\end{array}$ \\
\hline $0-35$ & 8 & 3.02 \\
$35-40$ & 11 & 4.15 \\
$40-45$ & 10 & 3.77 \\
$45-50$ & 15 & 5.66 \\
$50-55$ & 35 & 13.21 \\
$55-60$ & 49 & 18.49 \\
$60-65$ & 34 & 12.83 \\
$65-70$ & 23 & 8.68 \\
$70-75$ & 16 & 6.08 \\
$75-80$ & 19 & 7.17 \\
$80-85$ & 14 & 5.28 \\
$85-90$ & 15 & 5.66 \\
$90-95$ & 9 & 3.40 \\
$95-100$ & 7 & 2.64
\end{tabular}




\begin{tabular}{ll} 
Mean TE (\%) & 63.24 \\
Minimum TE (\%) & 32.70 \\
Maximum TE (\%) & 97.10 \\
Standard Deviation of & \\
Firm Specific TE & 13.25 \\
\hline
\end{tabular}

Source: Authors' estimates based on primary data using econometric package FRONTIER 4.1 for Windows.

\section{Appendix 2 \\ The Trans-log Stochastic Production Frontier}

The stochastic production frontier developed separately by Aigner, Lovell and Schmidt (1977) and Meeusen and van den Broeck (1977) decomposes the error term of the usual econometric production function model into a white random noise component and a one sided inefficiency random component. For the present, we assume a cross-sectional stochastic production frontier model (specified in Kumbhakar et al, 1991) as

$\ln y_{i}=\ln f(x ; \beta)+v_{i}-u_{i}$

$u_{i}=\gamma^{\prime} z_{i}+\varepsilon_{i}$

The random noise component in the production process is introduced through the error component $v_{i}$ which is iid $N\left(0, \sigma_{v}^{2}\right)$ in equation (2.1). The second error component which captures the effects of technical inefficiency has a systematic component $\gamma^{\prime} z_{i}$ associated with the firm specific variables and exogenous variables along with a random component $\varepsilon_{i}$. Inserting equation (2.2) in (2.1) gives the single stage production frontier model

$\ln y_{i}=\ln f\left(x_{i} ; \beta\right)+v_{i}-\left(\gamma z_{i}+\varepsilon_{i}\right)$.

The condition that $u_{\mathrm{i}} \geq 0$ requires that $\varepsilon_{i} \geq-\gamma^{\prime} z_{i}$ which does not require $\gamma^{\prime} z_{i} \geq 0$ for each producer. It is now necessary to impose distributional assumptions on $v_{\mathrm{i}}$ and $\varepsilon_{\mathrm{i}}$ and to impose the restriction $\varepsilon_{i} \geq-\gamma^{\prime} z_{i}$ in order to derive the likelihood function.

Kumbhakar et al (1991) imposed distributional assumptions on $v_{\mathrm{i}}$ and $u_{\mathrm{i}}$ and ignored $\varepsilon_{i}$. They assumed that $u_{i} \sim$ $N^{+}\left(\gamma^{\prime} z_{i}, \sigma_{u}^{2}\right)$ i.e., the one-sided technical inefficiency error component has truncated normal structure with variable mode depending on $z_{i}$. It is still not necessary that $\gamma^{\prime} z_{i} \geq 0$. If $z_{1 i}=1$ and $\gamma_{2}=\gamma_{3}=\cdots \cdots \gamma_{Q}=0$, this model collapses to Stevenson's (1980) truncated normal stochastic frontier model with constant mode $\gamma_{1}$, which further collapses to the Aigner, Lovell and Schmidt (1977) half normal stochastic frontier model with zero mode if $\gamma_{1}=0$. Each of these restrictions can be statistically tested. Finally if $u_{i}$ and $v_{i}$ are independently distributed, all parameters of equation (2.1) can be estimated by using maximum likelihood estimation method. The log likelihood function is a simple generalization of that of Stevenson's (1980) truncated normal model having constant mode $\mu$, with only one change. Constant mode $\mu$ is now replaced by the variable mode $\mu_{i}=\gamma^{\prime} z_{i}$, so that the $\log$ likelihood function is

$\ln L=$ cons $\tan t-\frac{N}{2} \ln \left(\sigma_{v}^{2}+\sigma_{u}^{2}\right)-\sum_{i=1}^{N} \ln \Phi\left(\frac{\gamma^{\prime} z_{i}}{\sigma_{u}}\right)+\sum_{i=1}^{N} \ln \Phi\left(\frac{\mu_{i}^{*}}{\sigma^{*}}\right)-\frac{1}{2} \sum_{i=1}^{N}\left(\frac{\left(e_{i}+\gamma^{\prime} z_{i}\right)^{2}}{\sigma_{u}^{2}+\sigma_{v}^{2}}\right)$

where $\mu_{i}^{*}=\frac{\sigma_{v}^{2} \gamma^{\prime} z_{i}-\sigma_{u}^{2} e_{i}}{\sigma_{v}^{2}+\sigma_{u}^{2}}, \sigma^{* 2}=\frac{\sigma_{v}^{2} \sigma_{u}^{2}}{\sigma_{v}^{2}+\sigma_{u}^{2}}$

and the $e_{i}=\ln y_{i}-\ln f\left(x_{i} ; \beta\right)$ are the residuals obtained from estimating equation (2.1) simply by OLS. The $\log$ likelihood function of (2.4) can be maximized to obtain ML estimates of $\left(\beta, \gamma, \sigma_{v}^{2}, \sigma_{u}^{2}\right)$. These estimates can then be used to obtain producer specific estimates of technical efficiency, employing the Jondrow, Lovell, Materov and Schmidt (1982) approach to find the best point estimates of technical efficiency. These estimates are either 
$E\left(u_{i} / e_{i}\right)=\mu_{i}^{*}+\sigma^{*} \frac{\phi\left(\mu_{i}^{*} / \sigma^{*}\right)}{\Phi\left(\mu_{i}^{*} / \sigma^{*}\right)}$

or

$M\left(u_{i} / e_{i}\right)= \begin{cases}\mu_{i}^{*} & \text { if } \mu_{i}^{*} \geq 0 \\ 0 & \text { otherwise. }\end{cases}$

Once technical efficiency has been estimated, the effect of each exogenous or environmental variable on technical efficiency can be calculated from either

$\left[\partial E\left(u_{i} / e_{i}\right) / \partial z_{i k}\right]$ or $\left[\partial M\left(u_{i} / e_{i}\right) / \partial z_{i k}\right]$. Battese and Coelli (1995) model is an improvement over the Kumbhakar et al (1991) model as, (i) it is based on panel data and (ii) the non-negativity requirement $u_{i}=\left(\gamma^{\prime} z_{i}+\varepsilon_{i}\right) \geq 0$ is modeled as $\varepsilon_{i} \sim N\left(0, \sigma_{\varepsilon}^{2}\right)$ with the distribution of $\varepsilon_{i}$ bounded below by the variable truncation point $-\gamma^{\prime} z_{i}$. Battese and Coelli (1995) have verified that this new distributional assumption on $\varepsilon_{i}$ is consistent with the distributional assumption on $u_{i}$ that $u_{i} \sim N^{+}\left(\gamma^{\prime} z_{i}, \sigma_{u}^{2}\right)$. We assume a translog production function with 6 inputs to specify the underlying technology. All the six inputs are already mentioned in the text.

$\ln f(x ; \beta)=\beta_{0}+\sum_{j=1}^{6} \beta_{j} \ln x_{j}+\sum_{j=1}^{6} \sum_{k=1}^{6} \beta_{j k} \ln x_{j} \ln x_{k}$

Here (2.7) is the translog technological specification assuming six inputs. Here $y_{i}$ represents paddy output of the $i^{\text {th }}$ cultivator over the studied cropping season.

Further $\gamma^{\prime} z_{i}=\gamma_{1}+\gamma_{2} z_{2 i}+\gamma_{3} z_{3 i}+\gamma_{4} z_{4 i}+\gamma_{5} z_{5 i}+\gamma_{6} z_{6 i}+\gamma_{7} z_{7 i}$

where, the $z_{i}$ 's are firm specific non-input variables which may influence the technical efficiency of cultivators. Specifically,

$z_{2 i}=$ Age of the cultivator, as a proxy for experience.

$z_{3 i}=$ Outstanding Loans of the cultivator as a measure of the degree of indebtedness.

$z_{4 i}=$ land leased in by the cultivator expressed as a percentage of total cultivated area.

$z_{5 i}=$ Education of the cultivator as measured by number of years of formal schooling.

$z_{6 i}=$ Self consumption of farm produce as a percentage of farm output - a proxy for farmers' distress, and finally

$z_{7 i}=$ Government support dummy (assuming 1 for farmers receiving agricultural extension services and 0 for not receiving any such support). From the translog production function given by (2.7) we calculated the elasticities of output with respect to each input by using the relation

$\eta_{j}=\partial \ln Y_{i} / \partial \ln x_{j}=\beta_{j}+\sum_{k=1}^{6} \beta_{j k} \ln x_{k}$

All the factor elasticities are computed from estimated parameters and sample mean value of inputs. 